\title{
ENERGIA NUCLEAR: DESAFIO ATUAL, UNIVERSALIZAÇĀO E MEDO SOCIAL
}

\author{
Lucas Emanuel Goecking Liesner de Souza ${ }^{1}$ \\ Pontifícia Universidade Católica de Minas Gerais (PUC-MINAS) \\ Carolina Carneiro Lima² \\ Escola Superior Dom Helder Câmara (ESDHC) \\ Artigo recebido em: 10/01/2019. \\ Artigo aceito em: 07/03/2019.
}

\section{Resumo}

A energia alicerce condicional da vida senvolvimento Sustentável”. O método é, constantemente, reinterpretada para melhor atender à vontade humana. A eletricidade forma mais comum de energia atualmente garante bem-estar e dignidade humana. Seu alcance, entretanto, é limitado, já que nem todos usufruem deste bem. Universalizar o acesso à energia, produzindo-a com menos impactos negativos, é o grande desafio atual. Por isto, o objetivo geral é analisar a fonte nuclear, forma alternativa de produçáo de energia, subutilizada no país, mas, que representa uma alternativa sustentável, frente às externalidades da geração de eletricidade. $\mathrm{O}$ sustentáculo teórico adotado é o princípio do desenvolvimento sustentável, sob a ótica constitucional da obra de Ignacy Sachs, "Caminhos para o Deé o teórico-descritivo, por meio de pesquisas bibliográficas e normativas para responder ao problema sobre as razóes de se fomentar a produçáo de energia elétrica por fonte nuclear no Brasil. Esta fonte, em função da sua densidade energética, detém um potencial gerador superior às fontes ou à matriz principal brasileira. Com impactos negativos passíveis de mitigação, reflexos sociais e econômicos benéficos e certa independência em relaçáo aos ciclos naturais, a energia nuclear possui as características essenciais para as mudanças almejadas.

Palavras-chave: energia nuclear; desenvolvimento sustentável; acesso à energia elétrica; energias alternativas; princípio da informação.

\footnotetext{
1 Especialista em Direito Público pela Pontifícia Universidade Católica de Minas Gerais (PUC-MINAS). Bacharel em Direito pela ESDHC. Advogado com dedicação e atuaçăo exclusiva no setor de infraestrutura de energia elétrica no Brasil. ORCID: https://orcid.org/0000-0002-1334-2785 / e-mail: lkemanuel@hotmail.com

2 Mestre em Direito Ambiental e Desenvolvimento Sustentável pela Escola Superior Dom Helder Câmara (ESDHC). Especialista em Direito Público com ênfase em Direito Constitucional pela Universidade Cândido Mendes. Graduada em Direito pela PUC-MINAS. Professora Assistente I da PUC-MINAS. Assessora de Juiz no Tribunal de Justiça do Estado de Minas Gerais, Primeira Instância. ORCID: https://orcid.org/0000-0002-1619-7958 / e-mail: carolcarneirolima@yahoo.com.br
} 


\section{NUCLEAR ENERGY: CURRENT CHALLENGE, UNIVERSALIZATION AND SOCIAL FEAR}

\section{Abstract}

The energy conditional foundation of life is constantly reinterpreted to better meet the human will. The most common form of energy electricity currently guarantees human well-being and dignity. Its scope, however, is limited, since not all enjoy this good. Universalizing access to energy, producing it with fewer negative impacts, is the major challenge today. For this reason, the general objective is to analyze the nuclear source, an alternative form of energy production, underutilized in the country, but which represents a sustainable alternative to the externalities of electricity generation. The theoretical underpinning adopted is the principle of sustainable development, under the constitutional view of Ignacy Sachs's "Paths to
Sustainable Development". The method is the theoretical-descriptive, through bibliographical and normative research to answer the problem about the reasons of fomenting the production of electric energy by nuclear source in Brazil. This source, due to its energy density, holds a generating potential higher than the Brazilian main sources or matrix. With negative impacts that can be mitigated, beneficial social and economic impacts and a certain independence from natural cycles, nuclear energy has the essential characteristics for the desired changes.

Keywords: nuclear energy; sustainable development; access to electricity; alternative energies; principle of information.

\section{Introduçáo}

A geração de energia insere-se nos mais desafiadores problemas atuais. Amálgama importante tarefa no crescimento de riquezas dos povos, assim como as degradaçôes ambientais. A difícil virtude de conciliar a produção energética ao desenvolvimento sustentável vem se mostrando desgastada, principalmente, no cenário brasileiro. Levando em consideração que a energia é notável bem e recurso necessário à vida. É indispensável, desta forma, planejar o uso dos recursos naturais com as tecnologias mais eficientes a fim de atender às geraçôes atuais e vindouras em razão de determinação do artigo 225 da Constituição da República Federativa do Brasil de 1998 (CRFB).

Com o aperfeiçoamento científico atual, novos horizontes são inaugurados, o que possibilita, à manufatura de energia elétrica, alcançar o equilíbrio entre geração e consumo. Dentre as alternativas modernas, o potencial elétrico extraído de fontes nucleares destaca-se, permitindo ao Estado e ao setor privado, suplantar a 
demanda crescente por energia. A energia nuclear, ou em outros termos, a energia proveniente da matéria atômica, permite algo inusitado no âmbito elétrico, pois náo é baseada na combustấo de hidrocarbonetos, não produz os poluentes usais como o gás carbônico, presente na queima dos combustíveis fósseis, podendo ser encontrada em duas modalidades: fusão e fissão dos núcleos elementares.

A termeletricidade nuclear desafia as energias eólicas, fotovoltaicas e hídricas, pois, além de deter um potencial superior em gerar grandes quantidades de energia em espaços relativamente compactos, náo se limita aos ciclos naturais, menos ainda à disposiçâa, já disputada, por água, recurso cobiçado e sobremaneira usufruído no território brasileiro. A seu turno, a energia nuclear, desponta em duas modalidades, fissão e fusão. $\mathrm{O}$ método de fissionar átomos radioativos não é novo na física, sua história origina propriamente de um subproduto da Segunda Grande Guerra Mundial (1939-1945). Embora detenha problemas de custo, know-how de operação, segurança para com os resíduos tóxicos e a desativação do complexo da usina, continua, ainda hoje, representando grande parte da eletricidade usada no mundo.

É fundamental esclarecer o motivo de fomentar o uso da fissão nuclear, em um primeiro momento no Brasil. Fissionar os radioisótopos é uma das medidas adotadas por outros países, pois consagra o viés alternativo de se produzir eletricidade de grande monta, já que a tecnologia é mais acessível e consistente. O Brasil faz uso da fissão em Angra I e II, porém, a sociedade carece de informaçáo e de um mínimo de compreensáo acerca da energia nuclear, perdurando o medo que se mostra paralisante para a aplicaçáo deste formato de produçấo de energia. A fusão, por sua vez, é uma realidade distante, trata-se de uma inovaçáo única, entretanto, encontra-se em fase de estudos e testes. Sugerindo que a sua chegada no Brasil, seja vagarosa, por motivos de alto custo, da ausência de políticas públicas e pela educação socioambiental tímida. Portanto, a fissão (quebra de átomos de elementos radioativos), diferente da fusão (união dos átomos de hidrogênio, por exemplo) mostra-se a melhor opção em se produzir energia elétrica para o Brasil.

O objetivo da pesquisa é de fato conciliar, a deficiência em se gerar eletricidade no Brasil com os princípios da informação e do desenvolvimento sustentável ao promover o uso da eletricidade por fonte nuclear. Há uma cultura brasileira marcada pela construção de hidrelétricas que reforça a desinformação acerca das externalidades ao meio ambiente, por ambas as modalidades produtivas de eletricidade. Alçando a termeletricidade nuclear ao vazio do medo, fomentando hiatos factuais e empecilhos a universalizaçấo da energia.

Os capítulos abordaráo a história por de trás da energia desde os tempos primitivos até hoje e como ela acompanhou a humanidade. Compreendendo, 
também, as externalidades sociais, econômicas e ambientais da fissão nuclear e o porquê das dificuldades em se ampliar a produçáo de energia pela fonte nuclear no Brasil. Discutindo, após explicitar o processo fissionável, a facilidade em possibilitar o acesso universal a energia elétrica, bem como as suas repercussões econômicas, dentro do contexto nacional. Não se olvidará da aceitação social, fator de relevante importância para a matriz energética que no caso da fonte nuclear carrega consigo um legado de medo e traumas coletivos.

O método é teórico-descritivo, pois requer a abordagem técnica acerca da fissão nuclear, sua aplicação a lógica socioeconômica e legislativa brasileira, aplicando o caráter do desenvolvimento sustentável. As pesquisas são bibliográficas e normativas. O parâmetro basilar é oriundo da interpretação da Constituição da República de 1988, elegendo como marco teórico o princípio do desenvolvimento sustentável e a obra do autor Ignacy Sachs (2009a), Caminhos para o desenvolvimento sustentável, visando responder ao problema de o porquê fomentar a produçáo de energia elétrica por fonte nuclear no Brasil?

A humanidade requer uma mudança, náo só na forma de se gerar a energia elétrica, mas, na maneira pela qual reconhece os recursos disponíveis no planeta terra. O meio ambiente encontra-se, dentro de alguns parâmetros, é comprometido em sua sustentabilidade e países como o Brasil precisam fornecer eletricidade a milhares de pessoas, o que exige o aperfeiçoamento de todo o ciclo existente, desde a geração até o consumo energético.

Assim, a hipótese aponta a fissão nuclear como uma forma de energia alternativa eficiente, permitindo o aproveitamento de um potencial gerador significativo face aos entraves naturais, com impactos negativos conhecidos e passíveis de mitigação, atendendo, portanto, às necessidades do desenvolvimento sustentável e da universalidade do acesso à energia.

\section{A história da produçáo de energia elétrica por fonte nuclear}

A conquista tecnológica que permitiu a diferenciação categórica entre o presente e o pretérito foi a energia. O seu domínio e a sua produção em larga escala provocaram externalidades, grandes alteraçóes na ordem geopolítica mundial, sempre gerando impactos positivos e ou negativos. Além disso é responsável pelo contexto social, econômico e ambiental vigente. A história da energia teve seu grande marco não faz muito tempo, entre os séculos XVIII e XIX.

Até pouco antes de 1800 tudo que era fabricado dependia do trabalho manual, retirado da força humana ou animal. Todo o gasto energético era sustentado 
pela agricultura, a energia era consumida pelo ser humano advinha da caloria obtida nos alimentos. Na medida em que, a demanda por alimentos subia, qualquer que fosse o motivo, a mão de obra bruta era intensificada, exigindo mais comida. Com o decorrer do tempo e com o avanço tecnológico, novos instrumentos surgiram para facilitar as atividades mais penosas como os moinhos de água e vento.

Entretanto com a revoluçáo industrial e a descoberta da energia armazenada em substâncias químicas extraídas dos recursos naturais passamos a substituir a energia sustentável proveniente do sol e a da água, por uma energia mais barata, porém mais degradante ao meio ambiente oriunda de fonte fóssil. Utilizada ainda hoje, é eminentemente poluente e não renovável, sendo encontrada no carvão, petróleo e demais derivados de mesma matriz natural.

A Revolução Industrial, naturalmente, não é apenas a história da força a vapor, mas foi ela que deu início a tudo. Mais do que qualquer outra coisa, permitiu-nos superar as limitaçóes da força bruta, humana e animal, e gerar quantidades incríveis de energia útil a qualquer momento. Isso levou a fábricas e produção em massa, bem como ferrovias e transporte em massa; levou, em outras palavras, à vida moderna. A Revolução Industrial trouxe consigo a primeira era das máquinas da humanidade - a primeira vez que nosso progresso foi impulsionado, principalmente, pela inovação tecnológica - sendo o tempo de transformação mais profunda que nosso mundo já viveu (BRYNJOLFSSON; McAFEE, 2015, p. 7).

Dentre as mais acentuadas transformaçóes proporcionadas pela revolução das máquinas ou científica a termeletricidade nuclear é a grande campeã. Ela acabou envolvendo não só o setor energético, mas o poderio militar (bélico) de diversos Estados. Historicamente surge em 420 a.C. com Demócrito, filósofo naturalista da Grécia Antiga autor da teoria de que toda substância viva ou não, conservava em si uma estrutura comum a todos os outros seres. O componente universal de toda matéria foi chamado pelos gregos de átomo.

Em sua gênese a palavra átomo (do grego - atomos) sintetiza algo que é indivisível e inquebrável. $\mathrm{Na}$ ótica filosófica de Demócrito era a origem formadora de todo o cosmos, ou seja, tudo aquilo passível de compreensão, segundo a lógica dos gregos. Já no século XIX com uma abordagem completamente diferente, John Dalton, químico inglês, iniciou uma revisão atômica. Seus métodos demonstraram vários elementos agregando-se para formar outras substâncias químicas. Pode concluir, assim, que cada elemento é constituído de átomos, as unidades básicas da matéria, tal como os gregos. 
Agora, porém, foi demonstrado que cada elemento detinha apenas um tipo de átomo, variando conforme o material analisado, sendo distintos em suas especificidades. Logo, as configuraçôes físicas e as propriedades químicas também variavam. Mais tarde a ciência acabou afastando a lógica filosófica do conhecimento da Física e da Química: "evidências concretas de que os átomos não eram esferas duras indivisíveis nem uma partícula elementar tomaram-se disponíveis no fim do século XIX, com as descobertas do elétron e da radioatividade" (HINRICHS; KLEINBACH; REIS, 2014, p. 529) $)^{3}$.

Foi finalmente com Joseph John Thomson (prêmio Nobel em Física de 1906), cientista britânico, que a nova era atômica para energia nuclear emergiu. Thomson permitiu sistematizar o entendimento da estrutura atômica, conhecida até hoje, por um modelo didático, comumente chamado de "pudim de passas". O estudo apresentava grandezas físicas e as reações no núcleo dos átomos, bem como os primeiros estudos com os elétrons. A hipótese atômica foi o liame científico para a descoberta da radioatividade natural e artificial, abrindo posteriormente espaço para a termeletricidade nuclear.

A descoberta da radioatividade natural ocorreu em 1896 por Becquerel. Mas foi o casal Pierre Curie e Marie Skladowska Curie que aprofundou e desenvolveu os principais estudos a seu respeito. Outro fato relevante para a física nuclear foi a descoberta da radioatividade artificial, em 1934, pelo casal Frédéric Joliot e Irène Curie. Ambos conseguiram vislumbrar a produção de radioatividade artificial, através de elementos nẫo-radioativos (RIBEIRO, 2004, p. 28).

O grande alvoroço decorrente do uso a radiação, na prática, ocorreu após a descoberta da sua manipulaçáo artificial. A matéria prima usada era proveniente de alguns minerais encontrados na crosta terrestre como o urânio, o estrôncio e o tório. A energia nuclear, chamada assim, por acontecer em reaçóes no núcleo dos átomos, é aquela que se desprende quando, numa reação nuclear, provocada artificialmente por partículas físicas produz, mudanças perceptíveis no mundo físico, como a emissão de calor e criação de outros elementos químicos.

Nuclear do latim nucleu, núcleo, formaram-se em português núcleo e nuclear. À simples menção da palavra, já nos lembramos de um invento terrível, a fissão nuclear, que levou à descoberta da bomba atômica, noticiada pela primeira vez numa carta enviada ao então presidente norte-americano Franklin Delano Roosevelt

3 Os aceleradores de partículas já comprovaram que o próton e o nêutron parecem ser compostos por partículas menores chamadas quarks 
e assinada, entre outros, pelo cientista Albert Einstein (SILVA, 2014, p. 336).

A reação nuclear pode ser provocada por meio de dois princípios físicos, valendo destacar, neste momento, o porquê da hipótese da presente pesquisa ser a fissão e não da fusão nuclear. A união de elementos químicos (fusão), ainda depende de melhorias e apuração das técnicas e mecanismos existentes no padrão científico atual. Seu custo de operação é alto e a lógica é idêntica aos fenômenos físicos ocorridos na superfície de estrelas, como o sol.

A principal característica da fusão é também o seu maior obstáculo no contexto científico atual ${ }^{4}$, temperaturas elevadas, próximas ou até maiores das encontradas no sol. Limitada pelas razóes apresentadas, a fusão torna-se impossível e improvável de ser utilizada, pelo menos nos próximos anos.

A primeira reação física fissionável autônoma, por sua vez, ocorreu em 1942 no reator da Universidade de Chicago, nos Estados Unidos da América. "A descoberta, em 1939, da fissão com sua liberação de grandes quantidades de energia foi um evento histórico. Fontes de energia enormes, porém, intocadas, pareciam estar ao nosso alcance [...]" (HINRICHS; KLEINBACH; REIS, 2014, p. 556). A fissão conhecida por intermédio da termeletricidade nuclear nasceu de um subproduto da 2a Grande Guerra Mundial deflagrada em 1945.

Apesar de ser usada como fonte principal de eletricidade em vários Estados desde o século passado, seu uso comercial no setor elétrico veio somente após os acontecimentos de Hiroshima e Nagasaki (agosto de 1945) cujos reflexos negativos para a humanidade não dispensam comentários.

Após a Guerra a euforia pela tecnologia físsil ficou sobrevalorizada, acreditou-se muito na rentabilidade e sustentabilidade dos projetos, do processo dos combustíveis, inclusive, para a geraçáo elétrica. Assim o reator da Universidade de Chicago foi novamente usado, agora como molde para os grandes reatores.

Em 1951, um reator experimental de grande porte ${ }^{5}$, próximo à cidade de Detroit nos (EUA), conseguiu gerar a primeira eletricidade de um processo físico nuclear fissionado. Outros projetos foram surgindo, como o submarino nuclear Nautilus de 1953. Até que finalmente em 1957 o primeiro reator a produzir e comercializar eletricidade por fissão foi finalizado, no Estado da Pensilvânia (EUA).

Em se tratando do Estado brasileiro o primeiro momento de contato da energia nuclear de forma institucionalizada foi com a ediçấo da Lei 1.310, de 1951, que criou o Conselho Nacional de Pesquisas - CNPq. Logo após o discurso, intitulado "átomos para a paz" de Dwight Eisenhower' na ONU em 1953, a

4 O ITER é um dos projetos mais ambiciosos do mundo no campo da energia, visa gerar eletricidade por fusão nuclear. Os cientistas pretendem alcançar as temperaturas necessárias com o uso de um Tokamak, um invólucro que permite a reação e a união dos elementos, capaz de efetivar as altas temperaturas e contê-las, no estado de plasma. A plataforma iter.org prevê a operaçăo do deutério-trítio no reator em 2035.

5 O reator da Universidade de Chicago serviu como protótipo depois para os grandes reatores físseis.

6 Ex-general norte-americano, Dwight D. Eisenhower foi o 34º Presidente dos Estados Unidos (1953-1961). 
preocupação brasileira em deter maior controle sobre a tecnologia e a geração de combustíveis físseis alcançou seu ápice e começou a ter êxito durante o governo de Juscelino Kubitschek - JK (1956-1961).

JK como presidente eleito determinou a criação do Instituto de Energia Atômica, por meio do Decreto 39.872 de 1956. E a Comissão Nacional de Energia Nuclear - CNEN que se tornaria uma autarquia pela Lei 4.118 de 1962. "No início do regime militar, o governo Castello Branco firmou tratados de acordo de cooperação de uso pacífico da energia nuclear. [...] bem como buscou a adesão do Brasil ao Tratado de Proscrição de Armas Nucleares na América Latina (Tratado de Tlatelolco)" (SANCHES, 2011, p. 234).

Em 1968 o governo brasileiro decide construir a sua primeira usina elétrica termonuclear, denominada de Angra I. Foi conectada à rede elétrica pela primeira vez em 1982. Angra II, por sua vez, entrou em operação no ano de 2001, compreendendo parte de um acordo entre Brasil e Alemanha celebrado em 1975, momento em que foram encomendados a compra de oito reatores. Em 1984, Angra III tem o começo de suas obras que perduram até hoje.

Com impactos negativos mitigáveis, a termeletricidade nuclear, é uma das formas que se adequam ao princípio do desenvolvimento sustentável (considerado prima facie do Direito Ambiental). A sustentabilidade depende da harmonização de três vertentes: "[...] os critérios de relevância social, prudência ecológica e viabilidade econômica [...]” (SACHS, 2009a, p. 35). A instrumentalidade que o princípio concede e também exige nas atividades antrópicas, "talvez seja”, a mais importante das éticas socioambientais. Pois pauta-se em uma responsabilidade presente e futura ou sincrônica e diacrônica, respectivamente.

Sincrônica pois tem como ponto de partida a realidade atual, deficitária em produzir eletricidade, portanto, limitada na garantia de uma vida digna aos seres humanos. Assim o acesso universal da energia elétrica perpassa necessariamente a sustentabilidade sincrônica e diacrônica. Exigindo que as pessoas escolham (sabiamente) dentre as alternativas atuais, patenteando o contexto futuro da humanidade. A sobrevivência e a dignidade das gerações atuais e construção das geraçôes futuras depende, eminentemente, da ação presente em promover práticas ecologicamente mais sustentáveis, sendo a energia nuclear uma delas.

É a garantia da dignidade humana de ter acesso universal a energia elétrica, seja pela fonte nuclear ou qualquer outra. Desde que através do tempo as pessoas possam ser acauteladas pelos benefícios socioambientais, tutelando-se assim um ambiente ecologicamente protegido para as atuais e as futuras geraçôes.

Ao passo que é consolidado, através da ótica termelétrica nuclear, entre outros princípios a informação, a prevenção e a precaução à população, ao privilegiar o espaço decisório, do uso da radiação, de forma consciente na e para a comunidade. 
A Conferência das Naçôes Unidas sobre o Ambiente Humano, de 1972, ocorrida em Estocolmo, colocou a dimensão do meio ambiente na agenda internacional. Ela foi precedida pelo encontro Founex, de 1971, implementado pelos organizadores da Conferência de Estocolmo para discutir, pela primeira vez, as dependências entre o desenvolvimento e o meio ambiente, e foi seguida de uma série de encontros e relatórios internacionais [...]. À ética imperativa da solidariedade sincrônica com a geração atual somou-se a solidariedade diacrônica com as geraçóes futuras e, para alguns, o postulado ético de responsabilidade para com o futuro de todas as espécies vivas na Terra (SACHS, 2009a, p. 48-49).

Mesmo com os benefícios para o desenvolvimento sustentável o que marca a energia nuclear são os seus fortuitos acidentes, não raras as vezes de ordem humana. O caso brasileiro ocorrido no estado de Goiânia (setembro de 1987) ilustra muito bem a irresponsabilidade com o poder da radiação nuclear. Tecnicamente não se tratou de um acidente nuclear das mesmas proporçôes que Chernobyl ${ }^{7}$.

O incidente do Césio $^{137}$, como ficou conhecido no Brasil, ceifou inúmeras vidas e deixou outras muitas com complicaçôes médicas. Isto porque um aparelho radiológico foi retirado de uma clínica desativa e aberto por duas pessoas que venderam as peças para um "ferro-velho". A luz azul brilhante, emitida pelo elemento químico radioativo, chamou a atenção das pessoas locais, mal sabiam elas que se tratava do início de uma grande lástima.

O mais recente, ocorrido em Fukushima - Japão (março de 2011), originou-se de um terremoto (de magnitude 9.0 o quinto maior já registrado no planeta) seguido de um tsunami. Estes eventos trouxeram rachaduras ao complexo da usina, inclusive falhas aos mecanismos de segurança instalados nos reatores. Houve vazamento de radiação (posteriormente contida), mas em proporçôes muito menores e menos gravosas daquelas ocorridas em Chernobyl (abril de 1986).

Desde o uso militar da tecnologia e com os desastres ocorridos as dificuldades em se viabilizar empreendimentos elétricos de origem radioativa são grandes. $\mathrm{O}$ uso pacífico da radiação encontra indubitavelmente várias celeumas, ao mesmo tempo que apresenta externalidades que solucionariam problemas históricos (alguns países ainda hoje geram mais da metade de sua eletricidade a partir da fissão $)^{8}$.

\footnotetext{
7 Foi o pior acidente nuclear da história, estudos técnicos da época já criticavam os reatores usados em Chernobyl construída em 1983 (sendo ausente um vaso de contençáo adequado para suportar a explosão do núcleo). E em 26 de abril de 1986 após uma série de testes, não autorizados, questionados por especialistas o reator tornou-se instável. 8 A França é um dos principais exemplos, com 77\%, a Coreia do Sul próximo de 35\% e a Alemanha, cerca de 30\%. O Japão provia, antes de 2011,30\% de sua eletricidade. Em 2011, havia 442 reatores em operação no mundo. Sessenta e oito reatores estão em construçăo (HINRICHS; KLEINBACH; REIS, 2014, p. 558).
} 


\section{Impactos ambientais e socioeconômicos da energia por fissão nuclear}

Toda atividade antrópica gera repercussōes, imediatas, no espaço físico e mediatas no âmbito socioeconômico. Ambas são diferidas por um lapso temporal, muito embora, sejam próximas, em termos de externalidades. $\mathrm{O}$ conceito de externalidade foi concebido pelo economista inglês Arthur Cecil Pigou' em 1920. Tratam-se de açôes derivadas de outros sistemas, externos ao sistema originário de produção, que lhe deu causa (MOURA, 2011).

As externalidades e os impactos são reflexos perceptíveis no mundo fático, independentes, da sua causa fundadora, possuem imensa importância cognitiva, como por exemplo, as de vinculaçấo ambiental. Diferentemente daquilo que é comumente divulgado os impactos podem ser tanto benéficos como prejudiciais. Seu conceito no Brasil é definido pela Resolução no 1 de 1986 do Conselho Nacional do Meio Ambiente - CONAMA.

Artigo $1^{\circ}$ - Para efeito desta Resoluçáo, considera-se impacto ambiental qualquer alteração das propriedades físicas, químicas e biológicas do meio ambiente, causada por qualquer forma de matéria ou energia resultante das atividades humanas que, direta ou indiretamente, afetam:

I - a saúde, a segurança e o bem-estar da população;

II - as atividades sociais e econômicas;

III - a biota;

IV - as condiçôes estéticas e sanitárias do meio ambiente;

$\mathrm{V}$ - a qualidade dos recursos ambientais (BRASIL, 1986).

Há muitas críticas acerca do conteúdo proposto pelo referido ato normativo, sua inexatidáo é o grande descontentamento entre os estudiosos e profissionais. Não é por acaso que o seu conceito deôntico é, não raras as vezes, reinterpretado na técnica avaliativa dos impactos ambientais.

Categoricamente, o texto normativo apresenta uma definição de poluição, basta retomar a menção a seguir: "qualquer forma de matéria ou energia" incumbida da "alteração das propriedades físicas, químicas ou biológicas" do ambiente. De forma contrária, a definição de poluição apresentada pela Lei da Política Nacional do Meio Ambiente (Lei no 6.938 de 1981) corresponde a um conceito de impacto ambiental, no que tange somente ao impacto negativo. Como se sabe, impacto ambiental também pode ser positivo (SÁNCHEZ, 2008, p. 30-31).

9 A ideia foi desenvolvida no livro The Economics of Welfare publicado em 1920, pela editora Macmillan. 
Ao voltarmos a estes paradigmas no âmbito de geração de energia, sobretudo as utilizadas na atualidade, o princípio do desenvolvimento sustentável, não se torna uma mera faculdade, mas, sim algo cogente que exige observância. A realidade complexa e truncada pode ser vislumbrada na divisão de atribuição e pelo comportamento dos agentes públicos frente às metas estabelecidas:

Operadas pela Eletronuclear, subsidiária da estatal Eletrobrás, as usinas nucleares de Angra I (660 MW) e Angra II (1350 MW) foram responsáveis em 2003 por 3,6\% da eletricidade no país. A usina de Angra III (1350 MW), prevista para entrar em operação em 1998, năo foi terminada ainda e contém US\$ 700 milhóes em equipamentos embalados. Os investimentos diretos em energia nuclear não são muito mais elevados do que numa grande hidrelétrica. Contudo, o enriquecimento do urânio, o reprocessamento, o armazenamento de lixo atômico e sobretudo riscos causam os principais custos. A usina de Angra III teria potência nominal de $1350 \mathrm{MW}$, igual a de Angra II. A retomada das obras foi aprovada pelo Conselho Nacional de Política Energética (GOLDEMBERG, 2012, p. 185).

A viabilidade de projetos mais efetivos na prestação elétrica, como as de fonte radioativa - físsil, historicamente no Brasil e no mundo, seguem por um caminho intricado. Isto se deve não só a cultura do medo criada e depositada sob a tecnologia ou ao custo, mas, especificamente no caso brasileiro, do conforto em deter o know-how hídrico. O que se perpetua no Brasil, hodiernamente, é uma política-cultural monopolista pautada na hidroeletricidade ${ }^{10}$ (há funcionando, hoje, apenas duas usinas nucleares físseis Angra I e II).

A hidroeletricidade foi eficiente. Hoje, sozinha, não é mais. Então, a revisão de uma matriz até então eficiente e sustentável por ser baseada em fonte renovável, necessita de investimentos e informaçóes (participação democrática) para a sua implantação. O parâmetro, engessado, adotado para o setor elétrico brasileiro, dificulta, a gestão sustentável dos recursos naturais e econômicos do país.

Não obstante as hidrelétricas utilizarem uma fonte primária renovável, seus impactos negativos destoam mais do que aqueles produzidos pelas usinas físseis. Isto porque a energia nuclear detém um custo e desempenho de funcionamento mais efetivos do que as outras modalidades.

A habitualidade em usar as águas no Brasil, produz acentuados danos ambientais e por tabela danos sinergéticos percebidos em outros setores

10 Ideia defendida pela autora Carolina Carneiro Lima em sua dissertaçăo de mestrado na Escola Superior Dom Helder Câmara, requisito do título de Mestre em Direito (LIMA, 2017). 
socioambientais, igualmente importantes para o desenvolvimento do país. Em razão de existir externalidades negativas na matriz principal do país, fez-se imprescindível discorrer sobre os impactos da energia que se propóe neste estudo, principalmente, para que a decisão respeite o princípio da informação.

A democracia nasce e vive na possibilidade de informar-se. O desinformado é um mutilado cívico. Haverá uma falha no sistema democrático se uns cidadãos puderem dispor de mais informaçōes que outros sobre um assunto que todos têm o mesmo interesse de conhecer, debater e deliberar (MACHADO, 2006, p. 50).

Para o funcionamento, propriamente, do reator, a energia nuclear, náo se utiliza da queima dos hidrocarbonetos. Nem produz poluentes resultantes do processo de operação dos combustíveis fósseis. "[...] a produção de eletricidade a partir dos combustíveis fósseis predomina e é a principal fonte de poluentes. [...] a produção de eletricidade ainda tem um peso preponderante nas emissóes de $\mathrm{CO}_{2}$ pela queima de combustíveis fósseis no mundo" (GOLDEMBERG, 2012, p. 175). Mesmo com impactos ambientais moderados, a fissão, ainda, não é uma energia renovável ${ }^{11}$ e limpa, conquanto, sustentável se planejada a partir das análises ambientais, as quais, internalizam suas externalidades quando de um prognóstico.

Não há, de fato, formas em se gerar energia limpa, toda e qualquer fonte energética, produz, mesmo que mínimos, impactos socioambientais negativos. O que acaba ocorrendo na prática é a confusão conceitual com a energia renovável. Por isto é mais sensato utilizar o termo "produção mais limpa", introduzido pelo programa das Naçóes Unidas para o Meio Ambiente e pela Organização das Naçôes Unidas para Desenvolvimento Industrial na década de 80, motivado na Convenção de Estocolmo de 1972 (CUSTÓDIO; VALLE, 2015, p. 29-30).

Isto porque o maior problema ou dilema da tecnologia é o ciclo interdependente do combustível usado para o fissionamento de partículas radioativas - os radioisótopos. O urânio, principal mineral utilizado, é coletado de forma muito similar aos outros minérios metálicos (a céu aberto ou no subsolo).

Portanto o primeiro grande impacto da energia nuclear advém da mineração e o processamento dos combustíveis físseis ${ }^{12}$. Os quais degradam o solo e as formas

11 A fusão nuclear, por outro lado, é considerada o futuro da eletricidade, seu combustível renovável, é basicamente retirado da água, o deutério (D). "[...], na qual um em cada 6.500 átomos de hidrogênio é este isótopo. A fusāo completa de apenas $1 \mathrm{~g}$ de deutério (obtido de 8 galóes de água vai liberar a energia equivalente à queima de 2.400 galōes de gasolina” (HINRICHS; KLEINBACH; REIS, 2014, p. 652).

12 "Os produtos finais da reação de fusão são hidrogênio, hélio e nêutrons, por isso não temos que nos preocupar com os resíduos radioativos duradouros dos reatores de fissão, embora haja algumas partes radioativas do reator que 
de vida ali dependentes, ao consumirem no desenrolar da atividade, bastante água e combustíveis fósseis, na operaçáo do maquinário. Por outro lado, positivamente, a extração mineral gera muitos empregos e riquezas para a regiáo em que se encontra a mineradora, e posteriormente para a economia do país.

E em se tratando do urânio, após a lavra e o beneficiamento, seus valores despontam no mercado. Após a prospecção mineral (física) a fase de processamento é basicamente desempenhada por métodos químicos. Há um risco de contaminação das próprias substâncias usadas no beneficiamento do mineral quanto da geração do combustível final dedicado às usinas, mas são passíveis de controle. Ao mesmo passo que giram um setor econômico promissor pelos insumos e a mão de obra necessária.

O comportamento dos preços reflete a relação oferta/consumo, referente ao yellowcake. Os preços subiram de maneira acentuada durante a fase de expansão da construção de usinas nucleares, recuaram bruscamente na década de 80 e se mantiveram em baixa durante quase 20 anos, para registrar ligeira recuperação após o ano 2000 - período em que se nota um aumento no número de unidades instaladas e de MWh (megawatts-hora) produzidos (ANEEL, 2008, p. 123).

Manufaturado os combustíveis radioativos o reator físsil pode entrar em atividade. Mas primeiro é preciso erigir todo o complexo da usina, fundamental para o seu funcionamento seguro e coeso. A usina depende de várias camadas de concreto e aço capazes de conter eventuais externalidades ou mesmo acidentes, sejam eles oriundos do ambiente externo ou interno. Todo este sistema é ainda ligado aos instrumentos de resfriamento, pelo qual a água armazenada passa e é bombeada pelo vaso de pressão, aquecido, do reator. Este percurso gera um vapor que movimenta uma turbina ligada a um gerador obtendo-se a eletricidade.

Há aqui a ocorrência de impactos negativos ao meio ambiente, simplesmente pelo espaço que o complexo de uma usina nuclear ocupa. Seus impactos de edificação podem ser compensados e até mitigados ao passo que não precisam ser acopladas dentro ou conforme o ciclo habitual dos recursos naturais. Não interferindo, propriamente, nos fluxos hídricos, nos oceanos, na flora e na fauna, como outras fontes de energia.

Por outro lado, é demandado para sua implementação e funcionamento labor de diversas origens, dado socioeconômico positivo. Uma rede de termelétricas por fissão nuclear alavanca sobremaneira a economia de um país, até porque sua tecnologia influencia não só a produção de eletricidade, mas demais setores do país, como a agricultura, as universidades e a medicina. 
As usinas podem até ser implementadas próximas das regióes litorâneas e dos centros urbanos o que geraria economia de funcionamento na geraçáo e na entrega (linhas de transmissão) da eletricidade. Seu maior risco decorre de alguma falha no resfriamento das placas de fissão. Com o superaquecimento o núcleo, encontrado no vaso do reator, é fundido, sua explosão é iminente. Os danos provocados são locais e diferidos com a radiaçáo, como nos casos mencionados de Chernobyl e Fukushima.

Até porque dentro da normalidade do equipamento, o maior entrave é disposto primeiro no aproveitamento, uso ou reuso e posterior descarte do combustível físsil; segundo no descomissionamento do complexo nuclear, pois cabalmente a usina dispóe de uma vida útil. "A licença de operação tem, geralmente, a duração de 35 a 40 anos, com possibilidade de renovação por 20 anos" (HINRICHS; KLEINBACH; REIS, 2014, p. 587).

Explicitadas as externalidades ambientais e socioeconômicas do uso desta modalidade de produção elétrica há um elemento, eminentemente ligado ao Estado brasileiro, portanto finalístico, face a geopolítica do país, qual seja, a disponibilidade do mineral combustível. Não fazendo sentido algum para um país que já possui usinas em funcionamento, portanto detém o know-how, possuir apenas duas usinas termonucleares em operação, o que ratifica a expansão do seu potencial físsil represado.

Dentre as variáveis estipuladas pela Nuclear Energy Agency - NEA, órgão da Organization for Economic Co-operation and Development - OECD o custo brasileiro (compreendendo as etapas extração, beneficiamento, transporte, custos ambientais, e outros) em comparativo a outros países (Austrália, Cazaquistão, EUA, Canadá, África do Sul, Nigéria, Namíbia, Rússia, Ucrânia, Uzbequistão, Jordânia) é economicamente viável. O Brasil é $9^{\circ}$ colocado dos países detentores de jazidas significativas de urânio asseguradas abaixo de US\$ 40 por quilograma de urânio. E ocupa o $5^{\circ}$ lugar em prováveis reservas existentes no subsolo, com custo entre $40 \mathrm{e}$ 80 dólares (BORGES, 2012, p. 111-114).

As informaçôes dos reais males da radiação devem ser apresentadas e esclarecidas, sendo que os impactos podem ser mitigados e até eliminados com as técnicas existentes e desenvolvidas após os acidentes de Three Mile Island, Chernobyl e Fukushima. Neste contexto de maior acesso às informaçóes, inclusive oriundas dos acidentes retro mencionados, verifica-se que o Brasil possui vasto potencial minerário e condiçóes adequadas para utilização da fonte mineral como insumo capaz de participar da matriz energética nacional no formato suplementar ou complementar, mostrando-se, ainda, fonte alternativa mais sustentável.

Assim, estar-se-á diversificando e fortalecendo a geração de energia no país, 
garantindo segurança e acesso universal à eletricidade. Com tais melhorias sociais que envolvem o bem-estar, propicia-se, por via transversa, uma maior e melhor informação sobre a tecnologia e combate-se o medo que ainda perdura na produção de energia nuclear.

\section{0 dilema em universalizar o acesso à energia elétrica pela fonte nuclear frente sua aceitação social}

A maioria dos indicadores de externalidades (sociais, econômicas e ambientais) está intimamente correlacionado ao consumo de energia per capita. As estatísticas levam em conta uma série de informaçōes, diferidas no tempo e espaço. $\mathrm{O}$ Índice de Desenvolvimento Humano - IDH, por exemplo, se vale da longevidade (expectativa de vida), da instrução (educação) e da qualidade de vida (poder de compra, baseado no Produto Interno Bruto - PIB de cada país).

Os critérios não são estáticos, anualmente, sofrem reinterpretaçóes para que as informaçôes adotadas sejam, de fato, um instrumento de mudança social real. As análises visam identificar as discrepâncias que impedem a melhora e a manutenção da estabilidade econômica, social e ambiental das naçôes. Em outros termos, o próprio desenvolvimento daquela naçáo associado a uma qualidade de vida melhor.

Portanto, mesmo sendo apenas indicadores, é possível, obter uma ideia de como anda o uso sustentável (ou não) dos recursos naturais, bem como, a gestão das fontes energéticas que refletem diretamente na qualidade de vida das pessoas, nos serviços públicos prestados, no regime democrático e em todo o aparato organizado do Estado (jurídico, político e econômico).

Projeçôes do Painel Intergovernamental de Mudanças Climáticas (IPCC, na sigla em inglês), diante do crescimento populacional mundial, apontam a necessidade de se quintuplicar o fornecimento de energia no mundo até 2050. Essa demanda maior deverá ocorrer em países emergentes como o Brasil, China, Índia e outros da América do Sul, Ásia e África. Esse cenário, associado às preocupaçóes com as mudanças climáticas e a escalada de preços de geração de outras tecnologias, provocou o ressurgimento de usinas nucleares para geração de potência. Atualmente, existem no mundo 443 usinas nucleares, correspondendo a $370 \mathrm{GW}$ (e) de potência nominal, que representam $17 \%$ da potência mundial instalada. No mundo, desde 1980, a produção nuclear de energia elétrica saltou de 0,7 milhão para 2,6 milhôes de GWh por 
ano. No Brasil, com a entrada em operação da usina Angra 2, em 2000, essa produção está em torno de 14 mil GWh por ano (CARAJILESCOV; MOREIRA, 2008, p. 33).

Esses padróes de medidas que são adotados surgem, também, de uma preocupação baseada a partir dos impactos ambientais provenientes da produção e utilização da energia. Mas, sobretudo, para a preservação da espécie humana sob o manto terrestre. Como já mencionado, em um curto lapso temporal (cerca de 150 a 200 anos após a Revolução Industrial) as externalidades de origem antropogênica se destacaram frente aos efeitos naturais do ambiente, muito em razão da sua amplitude e das formas de energia erigidas. "[...] nas consideraçóes do cientista russo Vernadsky: homem se tornou uma força de proporção geológicas" (GOLDEMBERG, 2012, p. 112), vale esclarecer que o patamar civilizatório ou antropológico atual, com todas as suas externalidades, positivas e principalmente negativas só foi possível graças a energia e o aprimoramento da mesma.

Dentre as variadas maneiras pelas quais a sociedade se organiza, a energia, em todas elas, não pode ser negligenciada ou até mesmo relativizada. Isto porque todo e qualquer processo civilizatório, hoje, depende da energia. Ao seu modo, a eletricidade, uma das espécies de energia, alcançou condição especial, quase genealógica para o nível de organizaçáo dos países hoje.

A lógica da convivência atual, baseada no consumo desenfreado de bens e serviços, faz com que a dependência por fontes energéticas cresça, mesmo que a população mundial se estabilize ou mesmo diminua. Isto porque o ciclo do consumo já tomou autonomia própria. Quanto maior a produção e os serviços gerados mais energia é necessária, para isto requer-se mais, do insumo básico - energia. $\mathrm{Na}$ tentativa de balancear ou mesmo equilibrar as equaçóes avassaladoras atuais o desenvolvimento sustentável é um paradigma decisivo.

Essa é a justificativa principal de se ter um sistema elétrico eficiente, seguro e assim funcional, conquanto, igualmente equilibrado desde a geração até a distribuição elétrica. E dado que a relação entre a energia e o desenvolvido da humanidade é amalgamada, podendo variar conforme cada cultura e regionalidade, estes parâmetros executivos e técnicos tornam-se essenciais para qualquer gestão governamental ao longo das políticas públicas.

Portanto a presença de um sistema de energia elétrica eficiente ou equilibrado e porque náo sustentável, jamais deixará de ser fundante e presente nas situaçóes mais comuns do cotidiano antropológico. A revolução tecnológica, ainda em andamento, desenvolvida por fontes energéticas e principalmente pela eletricidade só será destruidora ou negativa, quando da sua ausência, da má aplicação (ineficiência elétrica) ou mesmo do seu uso limitado pelas pessoas. Fatalmente 
e com infelicidade as práticas energéticas ao redor do mundo subsistem fora dos padróes da sustentabilidade, o quadro já acena retraídas mudanças, porém:

O consumo de energia pelo homem é, porém, a principal origem de grande parte dos impactos ambientais, em todos os níveis. Em uma escala micro, desencadeou, por exemplo, doenças respiratórias, com o uso primitivo de lenha. Num nível, é a principal fonte das emissóes de gases de efeito estufa, que intensifica as mudanças climáticas e causa perda de biodiversidade. Em algumas situações, a energia não tem um papel dominante, mas ainda assim é importante: é o caso, por exemplo, da degradação costeira e marinha, devida, em parte, a vazamentos de petróleo e outros desastres ambientais (GOLDEMBERG, 2014, p. 37).

Universalizar o acesso à eletricidade por si só já constitui um desafio técnico, político e econômico. Somado ao panorama globalizado e ao estado democrático, hodierno, o objetivo se torna progressivamente mais complexo e melindroso. Entretanto o acesso universal lograria o adimplemento de uma série de compromissos internacionais. Ademais, fixaria, após toda a inteligência analítica produzida no tempo, a conciliação do bem-estar humano com o meio ambiente natural, se e somente se, forem dirigidas por prismas de sustentabilidade sincrônicas e diacrônicas ${ }^{13}$.

No caso do Brasil, a exigência do acesso universal à rede elétrica é igualmente preocupante. Os índices mencionados, da precisão latente e crescente por energia, asseveram celeumas, paulatinamente, verticalizadas que envolvem a qualidade de vida do brasileiro. Tanto quanto a guarida legal, disposta, particularmente, no cerne da Constituiçấo da República de 1988, veja:

A Constituição da República Federativa do Brasil de 1988 - CR/88 - dedicou todo um capítulo ao assunto, e, no caput de seu art. 225, estabeleceu que "todos têm direito ao meio ambiente ecologicamente equilibrado, bem de uso comum do povo e essencial à sadia qualidade de vida", para, logo em seguida, impor "ao Poder Público e à coletividade o dever de defendê-lo e preservá-lo para as presentes e futuras geraçôes". Percebe-se, portanto, que a $\mathrm{CR} / 88$ não apenas consagrou o direito fundamental ao meio ambiente equilibrado como ainda o apontou como sendo condição para que alguém tenha qualidade

13 O desenvolvimento sustentável é aquele que proclama a conciliação entre o crescimento econômico, a preservaçáo do meio ambiente latu sensu e a equidade social, conjuntamente. "Esse tripé de ecodesenvolvimento é sustentado por um duplo conceito ético: de solidariedade sincrônica com todos os passageiros da nave espacial Terra e de solidariedade diacrônica com as geraçôes futuras" (SACHS, 2009b, p. 14). 
de vida, sem esquecer de destacar que a sua importância se estende para além da presente geração. Aqui convém apontar que o tratamento constitucional do tema autoriza dizer que a promoção do meio ambiente sustentável é um valor indissociável da própria concepçâo do Estado brasileiro (COUTINHO; MORAIS, 2016, p. 192).

Energia em sua acepção mais abrangente congloba não só o setor econômico, mas, as redes de distribuição, funcionamento de toda uma nação, sua soberania nacional (segurança territorial) e as políticas socioambientais. As quais devem surgir de um pressuposto de dignidade humana intergeracional, almejando, na medida do possível, a viabilização de técnicas e ferramentas mais eficientes e duradouras.

Salta na contemporaneidade o desafio de situar a população para um debate quanto aos avanços tecnológicos oriundos e correlatos do setor elétrico. Para isto é impreterível o elastecimento da dialeticidade de maneira franca e transparente, evidenciando todos os potenciais benéficos e por ventura malefícios em se gerar grandes massas de energia no mundo. Não há, por óbvio, outro modo de perpetrar o uso das fontes energéticas de maior complexidade sem a participaçáo e o conhecimento popular das suas externalidades.

O enquadramento atual brasileiro por energia elétrica (e também em âmbito internacional) além de ser discrepante na geração, carece de severas atualizações nas redes de transmissão (entrega final ao consumidor). O princípio do desenvolvimento sustentável, novamente, é trazido à baila, no intuito de inovar e proteger ao máximo o meio ambiente.

Quando se tem como pano de fundo a necessidade do uso de métodos tecnológicos inovadores. O Gráfico 1 demonstra o potencial de determinados combustíveis na produção elétrica, o destaque é ainda para as fontes radioativas:

Gráfico 1 Densidades energéticas de combustíveis.

Fonte: Tennenbaum (2009 apud BORGES, 2012, p. 104).

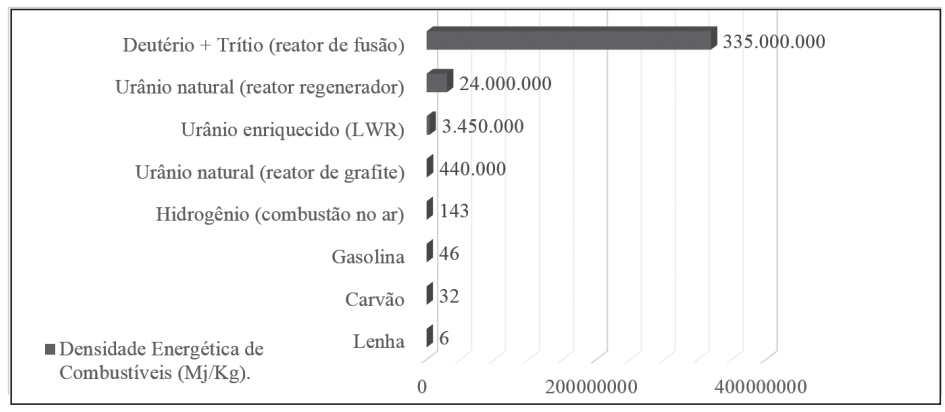


Quer dizer que 1 joule equivale a 1 watt/segundo, seguindo o gráfico a cada quilograma (KG), conforme o combustível, é gerado 1.000 joules. Ato contínuo $1 \mathrm{KG}$ de gasolina gera 46 megajoules (MJ) e $1 \mathrm{KG}$ de urânio enriquecido gera 3.450.000 MJ. Cruzando estes dados a geração de energia por fissão nuclear é exorbitante, uma vez que o urânio enriquecido dispóe de densidade energética superior a gasolina (BORGES, 2012, p. 104-105).

Sem embargos aos posicionamentos contrários quanto ao uso da termeletricidade nuclear, seu trato e compreensão carecem de elucidaçóes acessíveis às pessoas. Energia elétrica, por fontes radioativas, é uma realidade já há um bom tempo, seu abandono por completo, talvez seja, impensado e fatalmente um retrocesso legal. De tal forma que o núcleo do debate acerca do risco proveniente da tecnologia, se desenvolve a partir de um paradigma límpido, paritário e participativo da informação, dos atos que envolvem o interesse público e coletivo, veja:

O Conceito de Estado da informação Democrático de Direito abrange a informação democrática, onde a isonomia possibilite a todos, sem exceção, acessar a informaçáo existente, ou recebe-la, em matéria de interesse público ou geral. "Estado de Direito" porque tanto o acesso como a divulgação da informação não são absolutos, estando subordinados às normas legais preexistentes e à interpretação e decisão dos tribunais, nos casos conflitantes (MACHADO, 2006, p. 50).

Necessariamente o risco em se fornecer eletricidade é alto, todavia, quando sua origem é resultado da técnica fissionável de radioisótopos seu maior obstáculo, ao redor do mundo, depreende-se do medo. As razóes de temor estão esculpidas na história recente, vide os eventos de 11 de março de 2011, ocorridos, ao nordeste do Japão em Sendai, local do complexo nuclear de Fukushima Daiichi. Apesar disso, nenhum acidente, até hoje, que envolve energia nuclear e radioisótopos conseguiu alcançar os níveis nefastos de destruição no espaço e tempo ${ }^{14}$ do planeta terra como os de Chernobyl sucedidos em 1986.

As matrizes elétricas, atuais, compostas por usinas de fissão possuem, seguramente, procedimentos e mecanismos potencializados no âmbito da segurança, já que historicamente os maiores desastres envolvendo este tipo de produção elétrica decorreram de falhas humanas ou de acidentes naturais. As fatalidades existem, muito em conta do tipo da atividade, qual seja, manipulação da energia através matéria física dos átomos, por isto os cuidados preventivos e repressivos devem ser exaustivos.

Criar e distribuir a energia elétrica em qualquer parte do mundo possui riscos elevados de operação e execução. Por isto o montante financeiro requerido

14 Para uma leitura de tônica visceral, detalhes políticos e históricos, reais, sobre o palco de acontecimentos ocorridos em Chernobyl após a detonaçấo do reator de fissáo nuclear, vide Aleksiévitch (2016). 
para as operaçóes de fornecimento de energia, demandam altas quantias de capital e conhecimento técnico especializado. Sendo assim com o aumento dos índices de crescimento demográfico para os próximos anos, para diversos países, principalmente os em desenvolvimento, como é o caso do Brasil fontes alternativas mais sustentáveis e efetivas são imprescindíveis. Políticas públicas que envolvam ampliação do acesso à energia partindo da alteraçâo da densidade demográfica devem atentar-se as alternativas tecnológicas, cujo know-how técnico e científico é conhecido e dominado, como é o caso da energia nuclear devem ser utilizados. Para tanto suas características dentro do perfil da sociedade devem ser trabalhadas e esclarecimentos sobre as externalidades imediatas e potencias elucidadas.

Mesmo sendo a maior barreira em viabilizar a termeletricidade físsil, a aceitação social precisa e merece uma leitura consciente. Distante de ídolos, compreendido na atualidade, pela cultura (desmotivadora) do medo. "Para um filósofo grego, essa ideia teria parecido grotesca, completamente absurda, o ser humano tomado pela angústia, sendo o contrário do sábio. O medo nos torna tolos e maus, incapazes de pensar livremente, ou de nos abrir ao outro" (FERRY, 2015, p. 11).

É possível dizer, suscintamente, que a prevenção trata de riscos ou impactos já conhecidos e vistos pelo campo científico, já a precaução se distingue por gerir riscos ou impactos desconhecidos (MILARÉ, 2011). A energia nuclear dentre todo o seu histórico, foi paulatinamente sendo sedimentada e dominada dentro do campo tecnocientífico. Portanto o princípio da precaução ${ }^{15}$ não é o instrumento hábil, em toda sua plenitude teórica, mecanismo categórico para solucionar eventuais externalidades do uso da energia nuclear, quanto menos ser subvertido na ótica do medo.

Ainda conforme esse discurso corrente hoje em dia nos meios empresariais, outro lado, agora intelectual e moral, vem imobilizar o crescimento: a absurda inscrição do princípio da precaução na Constituição seria o símbolo de uma sociedade que cede pouco a pouco à ideologia funesta do risco zero. [...] é verdade que nosso continente parece tetanizado pela angústia, temos medo de tudo: do sexo, do álcool, do fumo, da rapidez, dos OGM [organismos geneticamente modificados], do buraco na camada de ozônio, das nanotecnologias, das micro-ondas, da Turquia, da globalizaçấo, do aquecimento global, das antenas celulares [...] e de mil coisas ainda abomináveis (FERRY, 2015, p. 9).

15 Precaução e Prevenção năo se confundem, há divergência semântica entre as expressōes, ao menos em termos etimológicos. "Prevenção é substantivo do verbo prevenir (do latim prae = antes e venire = vir, chegar), e significa ato ou efeito de antecipar-se, chegar antes; induz uma conotação de generalidade, simples antecipação no tempo é verdade, mas com intuito conhecido. Precaução é substantivo do verbo precaver-se (do latim prae $=$ antes e cavere = tomar cuidado), e sugere cuidados antecipados com o desconhecido, cautela para que uma atitude ou ação não venha a concretizar-se ou a resultar em efeitos indesejáveis" (MILARÉ, 2011, p. 1069). 
Uma leitura íntegra se faz necessária se o objetivo é consubstanciado em políticas energéticas que visem a universalização da eletricidade para os povos. Isto se faz jus, uma vez que, não há espaço para criaçáo de riscos inexistentes, o que é de fato, buscado desde os especialistas aos simpatizantes é o real potencial lesivo do empreendimento e não mitos, corroboradores dentro de um palco de especulaçóes.

O temor proveniente da tecnologia nuclear existe, sua origem, entretanto, demanda uma percepção apurada, para então quebrar as resistências desnecessárias a ela circundantes. $\mathrm{O}$ hiato ${ }^{16}$ do Brasil em gerar eletricidade de fonte nuclear, mitigando os famosos apagóes, deve abordar o espectro do medo. Estamos em uma sociedade que possui medo de tudo e que vacila rotineiramente em assumir sua responsabilidade para as consequências por elas geradas, basta observar os diversos danos ambientais já concretizados, envolvendo em sua maioria o setor elétrico.

A prisão que é estabelecida nas sociedades contemporâneas, através do medo, é erigida por dicotomias, problemas ou mesmo traumas pretéritos, assim, na ânsia por uma soluçấo ou resposta, utopias coletivas são erguidas. Por isto há quem diga ser contrário à tecnologia nuclear, mas não apresente fundamentos basilares que envolvam todo o seu processo técnico, econômico, social, político, jurídico e acima de tudo ambiental.

Os problemas de outrora, que envolvam a fissão nuclear, propriamente, como os acidentes de Chernobyl em 1986 e de Fukushima em 2011, mal relacionados com o público local e também mundial, em nenhum momento podem ser repassados, na intransigência de uma contra resposta, ou seja, serem resumidos a partir de um slogan de poucas palavras, escoimando detalhes indispensáveis a superação dos efeitos reais ocasionados por desastres radioativos no meio ambiente.

Longe de mim a ideia de negar a parte de verdade que reside nesse discurso sobre o peso exorbitante do Estado, bem como sobre a sacralização constitucional do princípio da precauçâa. [...] Estou, porém, convencido de que é preciso ir mais longe, muito mais longe na análise se quisermos compreender em toda a sua amplitude a verdadeira origem dos elementos que suscitam a tendência geral das sociedades modernas à mudança contínua, à inovação, mas também em todos os campos da existência humana - a arte, os costumes, os valores, o vestuário, a cultura, a informação, a tecnociência, a escola -, tudo o que é "ultrapassado" ou "démodé" sendo destinado à obsolescência ou ao museu (FERRY, 2015, p. 12).

16 A produçáo de eletricidade é responsável por pouco menos de $20 \%$ do consumo de energia primaria mundial e ainda dois bilhôes de pessoas não têm acesso a esse bem em todo o mundo, razáo pela qual programas de eletrificaçáo são prioritários (GOLDEMBERG, 2012, p. 175). 
Grande parte da população acha que é necessário hoje em dia, o medo como organizador social. O medo virou uma virtude no tempo atual, porque, foi criada uma cultura a partir dos grandes acontecimentos antropocêntricos dos últimos 250 anos de experimentação humana. Embora seja uma opção possível, sua escolha resulta no comodismo daquilo que já é dominado, mas que não necessariamente é o suficiente para abastecer as demandas sociais daquele momento e vindouras, assim, impedindo a criação inusitada, necessária dentro da fluidez das relações.

Zygmunt Bauman ${ }^{17}$ é um pensador Polonês cuja teoria possibilita uma análise mais atual das relaçóes no mundo contemporâneo. $\mathrm{O}$ referido escritor permite o estudo analítico através da ótica prática das formas de convivência na modernidade. Bauman tem escritos famosos desde dos anos 60, mas é a partir da década de 1990 que o mesmo insere na literatura internacional o termo modernidade líquida.

Bauman se vale da figura de linguagem (modernidade líquida) para compreender a vida compartilhada na atualidade. Segundo o sociólogo, a liquidez consagra a ideia de mudanças constantes, logo jamais haverá a fixação de um padrão ou forma a ser seguida ou perquirida, entretanto, há ao mesmo tempo a conservação de algumas características, constituidoras do âmago da liquidez antrópica. E é exatamente este conflito, intermitente, entre a mudança contínua, que conserva um núcleo duro de inalterabilidade, que o autor usa para explicar a modernidade.

A partir de Bauman é possível interpretar que os indivíduos estão vinculados e por isto incontingentes há alguns sistemas, dotados também, da lógica paradoxal, de alterabilidade e de inexorabilidade. Assim as noçôes ou interpretaçóes sobre determinados temas ou assuntos que envolvam a coletividade, e não há um tema sequer que não o seja, perpassam por dicotomias existenciais, imediatamente particulares, mas de repercussóes perceptíveis no seio social, logo, mediatamente plurais.

O conflito existente na coletividade gera sentimentos de índole social coordenados, portanto destrutivos, causando o que o autor considera propriamente como a ontologia do medo e da angústia (BAUMAN, 2007). Essas forças propulsoras de um querer duvidoso (medo e angústia) para as soluçôes dos problemas de convivência, conforto e bem-estar são impeditivas de um paradigma, portanto, de uma vida sustentável em qualquer seara.

O exemplo significativo brasileiro, intimamente, ligado ao setor de geração de eletricidade, é o viés questionável em privilegiar o know-how hídrico em

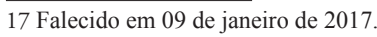


detrimento da fissão nuclear ou mesmo de outros modais, como o fotovoltaico e eólico. Há desta forma a permanência em se gerar a eletricidade, entretanto, o paradoxo reside nas formas extremamente impactantes e degradantes que as geram e que a longo prazo compelem a insustentabilidade de todo o sistema energético do país.

Há que se ter uma abertura de mentalidade para novas formas de geração de energia, objetivando a diminuição de impactos negativos pela diversificaçăo. Se náo é possível evitar todos os efeitos negativos reflexos da produçâo energética, e a coletividade de hoje mostra-se absolutamente dependente de energia em níveis cada vez maiores, além de uma educação ambiental bem-estruturada, faz-se prioritário pensar em modelos viáveis e menos impactantes, não minimizando o contexto exteriorizado de impacto à emissão de gases do efeito estufa, pois, como dito, o ambiente é muito mais diverso do que a qualidade do ar e o controle do clima na Terra (LIMA, 2017, p. 114).

A tấo dita responsabilidade ética, serviente de uma consciência coletiva, propícia da convivência equilibrada, parece a solução inovadora dos duros caminhos a serem experimentados pela humanidade. Porém não se trata de algo novo, a Constituição da República trata do tema e diversos autores revolvem este assunto, mas parece que a gestáo das informaçóes e do conhecimento se rendeu há algo pontual e vigente, mas que deve ser corrigido "a paralisia do medo do desconhecido deve ser combatida, numa sociedade democrática, através da análise objectiva dos riscos e da sua comunicação" (GOMES, 2013, p. 196).

O otimismo racional não pode ser descartado, nem incorrido, portanto, confundido com as penumbras de destruição oriundas dos impactos negativos trazidos pelas inovaçôes (RIDLEY, 2014). A gestão do ônus e do bônus sempre foi vital, hoje, suas dimensôes baseiam-se no padrão de vida almejado e conquistado pela humanidade. Frente a multiplicidade de quesitos sociais, econômicos e ambientais, a dialeticidade humana não pode ser rivalizada com os desafios gerados pela própria sociedade.

A reformulação da matriz energética não é necessária somente em razão da proteção ambiental, mas, sobretudo, em razão de outros direitos fundamentais como o acesso universal à eletricidade, o bem-estar alcançado por meio do mercado de produtos de consumo e a questấo de se impedir retrocessos no que tange a fatores vinculados à dignidade da pessoa humana e a conquistas sociais (LIMA, 2017, p. 59). 
Tal reflexão é a noção fundante para optarmos, ajuizados do papel e do apreço da sustentabilidade, face ao descontrole antrópico, obrigatoriamente ligado ao setor de energia de capa país.

\section{Consideraçóes finais}

Dentre as principais questóes ambientais contemporâneas a energia, na configuraçáo elétrica, imbui-se de tarefas substanciais garantindo e efetivando o bem-estar e a dignidade humana. Mesmo ao garantir condiçóes mínimas aos indivíduos, é importante destacar o custo operativo para a sua produção e para a manutenção do sistema. É inegável que a geração de eletricidade degrada o ambiente, possuindo externalidades sociais, econômicas e ambientais, tanto positivas quanto negativas. A diferença que se pode perceber encontra-se na forma de gestão que se destina esse setor, pelo Estado e pelo empreendedor.

Mesmo sendo um dos vários insumos principiológicos, dentro de uma cadeia produtiva, para a existência e continuidade das formas de vida, seu alcance, é diminuto, exíguo e às vezes inexistente, para grande parcela da populaçáo ao redor do planeta terra. Esta dicotomia deflagra a necessidade, premente, de universalizar o acesso à energia, entretanto, as produçóes energéticas de agora em diante devem ser assentadas dentro de um patamar de responsabilidade (civil, penal e administrativo) distinto dos anteriores, ou seja, mais consciente das externalidades, da importância de uma gestáo responsável e comprometida com a sustentabilidade do negócio, precipuamente em relação ao tema dos impactos.

A preservação ambiental, o crescimento econômico e a equidade social devem caminhar lado a lado. A noção de evolução e progresso até então, questionadas durante os séculos XIX, XX e intensamente agora no XXI não podem mais convergir ao absurdo, basicamente, desconsiderando o princípio do desenvolvimento sustentável. A natureza suporta ainda os surtos da industrializaçáo, que eclodiram no passado recente da história do mundo. E o cerne de qualquer política ambiental pautada na ótica sustentável deve, obrigatoriamente, partir das fontes de energia manufaturas em todo planeta, pois é a partir disto que qualquer bem ou sistema organizado de consumo se baseia.

É a energia que serve de base a todo o aparato industrial desde a revolução industrial, quando mais avançado for um país em gerar diversos tipos de energia, maior será seu poderio industrial e consequentemente político/militar. O porquê de fomentar a fissão nuclear como um dos múltiplos modais elétricos que um país pode executar, advém, prioristicamente, da sua densidade energética frente 
as outras maneiras de se conseguir energia. $\mathrm{O}$ custo benefício da termeletricidade radioativa é muito alto, mesmo diante condiçóes severas da natureza.

O Brasil assume a frente deste debate pois já detém conhecimento técnico, inclusive em operação no Estado do Rio de Janeiro, nas usinas termonucleares de Angra I e II. O contexto alça mais prosperidade dada a vantagem geoeconômica em dispor de grandes quantidades de combustível físsil. Mesmo que a continuidade de empreendimentos nucleares no Estado brasileiro seja tímida é uma opção válida e sustentável para ser levada à discussão pública, conjuntamente com a população que sofre de insuficiência e da má distribuiçấo da eletricidade em um país de proporçóes continentais.

A fonte nuclear é forma alternativa e mais limpa de produçáo de energia. Ainda é subutilizada no Brasil, mas, que retrata propósitos sustentáveis, em relação às externalidades verificadas na geração de eletricidade. É uma forte candidata a mitigar os apagóes brasileiros, chancelando o acesso universal à eletricidade e possibilitando a tão almejada estabilidade no abastecimento, fomentando investimentos para o país.

Nesse contexto, as fragilidades ambientais e operacionais, típicas do setor brasileiro, basicamente proeminentes e movidas por um viés particular das fontes energéticas (hidroelétricas e termelétricas - movidas à matéria orgânica) seriam repensadas.

As mudanças defendidas visam a segurança energética, tấo perquirida por muitos países. Mas que dependem do aval de uma população ativa - participativa e conhecedora das dimensóes e do feitio da tecnologia em destaque. A energia nuclear fissionável, ainda é o principal expoente mundial em garantir a funcionalidade das sociedades mais modernas, mesmo possuindo em seu histórico inúmeros contrapontos e uma origem de base militar.

A fusão nuclear, vista como o futuro da humanidade, do ramo radioativo propriamente, é táo inovadora, quanto a fissão. As condições de sobrevivência e preservação ambiental são muito bem adimplidas com os princípios sistêmicos da radioatividade, de tal maneira, que a mesma interage e provoca a revolução paradigmática em diversos campos científicos. Entretanto, para que sua implementação consciente ocorra, não só no Brasil, mas em todo o mundo, requerer-se-á necessária e imperativa superação dos medos e fantasmas, infundados, criados pelas pessoas. Basicamente a aceitação da angústia e o equilibro do medo em viver e conviver em um mundo dinâmico e prolixo como o atual. 


\section{Referências}

ALEKSIÉVITCH, S. Vozes de Tchernóbil. São Paulo: Companhia das Letras, 2016.

ANEEL - AGÊNCIA NACIONAL DE ENERGIA ELÉTRICA. Atlas de energia elétrica do Brasil. Brasília, DF: ANEEL, 2008.

BAUMAN, Z. Tempos líquidos. Rio de Janeiro: Zahar, 2007.

BORGES, M. A. S. Segurança energética no direito internacional. Belo Horizonte: Arraes, 2012.

BRASIL. Constituição da República (1988). Constituição da República Federativa do Brasil de 1998. 21. ed. In: Vade Mecum Acadêmico de Direito Rideel. São Paulo: Rideel, 2015. (Série Vade Mecum).

BRASIL. Ministério do Meio Ambiente. Conselho Nacional do Meio Ambiente. Instituto Brasileiro do Meio Ambiente e dos Recursos Naturais. Resolução Conama n. 001, de 23 de janeiro de 1986. Disponível em: <http://www.mma.gov.br/port/ conama/res/res86/res0186.html>. Acesso em: 11 abr. 2017.

BRYNJOLFSSON, E.; McAFEE, A. A segunda era das máquinas: trabalho, progresso e prosperidade em uma época de tecnologias brilhantes. Rio de Janeiro: Alta Books, 2015.

CARAJILESCOV, P.; MOREIRA, J. M. L. Aspectos técnicos, econômicos e sociais do uso pacífico da energia nuclear. Ciência e Cultura, São Paulo, v. 60, n. 3, set. 2008.

COUTINHO, C. M. C.; MORAIS, J. L. B. Direito fundamental ao meio ambiente como elemento constitutivo da democracia. Veredas do Direito - Direito Ambiental e Desenvolvimento Sustentável, Belo Horizonte, v. 13, n. 25, p. 173-198, 2016.

CUSTÓDIO, M. M.; VALLE, C. N. L. Energia renovável, energia alternativa e energia limpa: breve estudo sobre a diferenciaçấo dos conceitos. In: CUSTÓDIO, M. M. (Org.). Energia e Direito: perspectiva para um diálogo de sustentabilidade. Rio de Janeiro: Lumen Juris, 2015. p. 5-39.

FERRY, L. A inovação destruidora: ensaio sobre a lógica das sociedades modernas. Rio de Janeiro: Objetiva, 2015.

GOLDEMBERG, J. Energia nuclear: vale a pena? 7. ed. São Paulo: Scipione, 1994. 
GOLDEMBERG, J. Energia e desenvolvimento sustentável. São Paulo: Blucher, 2014. (Série Sustentabilidade, v. 4).

GOLDEMBERG, J.; LUCON, O. Energia, meio ambiente e desenvolvimento. 3. ed. rev. ampl. São Paulo: Edusp, 2012.

GOMES, C. A. A idade da incerteza: reflexôes sobre os desafios de gerenciamento do risco ambiental. In: LOPEZ, T. A.; LEMOS, P. F. I.; RODRIGUES JÚNIOR, O. L. (Coords.). Sociedade de risco e direito privado: desafios normativos, consumeristas e ambientais. São Paulo: Atlas, 2013. p. 195-212.

HINRICHS, R. A.; KLEINBACH, M.; REIS, L. B. Energia e meio ambiente. 5. ed. São Paulo: Cengage Learning, 2014.

LIMA, C. C. A interferência da cultura econômica monopolista na formação da matriz energética brasileira: o poder dos ventos como fonte alternativa e complementar de energia elétrica. Dissertaçấo (Mestrado em Direito Ambiental e Desenvolvimento Sustentável) - Escola Superior Dom Helder Câmara, Belo Horizonte, 2017.

MACHADO, P. A. L. Direito à informação e meio ambiente. Sáo Paulo: Malheiros, 2006.

MILARÉ, É. Direito do ambiente: a gestão ambiental em foco: doutrina, jurisprudência, glossário. 7. ed. rev. atual. e reform. São Paulo: Revista dos Tribunais, 2011.

MOURA, L. A. A. Economia ambiental: gestáo de custos e de investimentos. 4. ed. Belo Horizonte: Del Rey, 2011.

PIGOU, A. C. The economist of welfare. 4. ed. London: Macmillan, 1932.

RIBEIRO, V. M. Tutela penal nas atividades nucleares. v. 6. São Paulo: Revista dos Tribunais, 2004.

RIDLEY, M. O otimista racional: por que o mundo melhora. Rio de Janeiro: Record, 2014.

SACHS, I. Caminhos para o desenvolvimento sustentável. Rio de Janeiro: Garamond, 2009a. (Coleção Ideias Sustentáveis).

SACHS, I. Prefácio: Ecodesenvolvimento e Justiça Social no Brasil. In: PÁDUA, José Augusto (Org.). Desenvolvimento, justiça e meio ambiente. Belo Horizonte: UFMG; São Paulo: Peirópolis, 2009b. p. 13-15. 
SANCHES, L. A. U. Curso de Direito de Energia: da história, tomo I. São Paulo: Instituto Geodireito, 2011.

SÁNCHEZ, L. E. Avaliação de impacto ambiental: conceitos e métodos. São Paulo: Oficina dos Textos, 2008.

SILVA, D. De onde vêm as palavras: origens e curiosidades da língua portuguesa. 17. ed. Rio de Janeiro: Lexikon, 2014. 